\title{
Síndrome de Gorlin-Goltz: Diagnóstico e Hipóteses de Tratamento
}

\section{Gorlin-Goltz Syndrome: Diagnosis and Treatment Options}

\author{
João MENDES-ABREU ${ }^{1}$, Miguel PINTO-GOUVEIA², Cátia TAVARES-FERREIRA ${ }^{3}$, Ana BRINCA², Ricardo VIEIRA ${ }^{2,4}$ \\ Acta Med Port 2017 May;30(5):418-421 - https://doi.org/10.20344/amp.7521
}

\begin{abstract}
RESUMO
A síndrome de Gorlin-Goltz é uma patologia hereditária, rara, autossómica dominante de penetrância completa, com expressividade variável. Caracterizada pelo aparecimento de múltiplos basaliomas, cursa, frequentemente, com o desenvolvimento de queratoquistos. Depressões palmares/plantares, calcificações da foice cerebral, anomalias esqueléticas congénitas, constituem, igualmente, critérios de diagnóstico, embora menos frequentes. Este artigo expõe dois casos clínicos, envolvendo familiares diretos, referenciados após identificação de vários basaliomas e quistos maxilares. Estabelecido o diagnóstico, perante a identificação de três critérios major, o tratamento consistiu na excisão das lesões, seguida, num dos casos, da terapêutica com vismodegib, com remissão completa. A síndrome de Gorlin-Goltz é, assim, um desafio multidisciplinar, cuja morbilidade variável e o elevado risco de recorrência tornam fundamental o tratamento e vigilância. Contudo, o aparecimento de novas terapêuticas moleculares dirigidas trazem uma nova esperança no tratamento destes doentes.
\end{abstract}

Palavras-chave: Síndrome do Nevo Basocelular/diagnóstico; Síndrome do Nevo Basocelular/tratamento

\section{ABSTRACT}

The Gorlin-Goltz syndrome is a rare autosomal dominant hereditary condition, with complete penetrance and variable expressivity. Characterized by the appearance of multiple basaliomas, and often the development of keratocyst, it can also express itself by the presence of palmar/plantar depressions, calcification of brain sickle, and skeletal birth defects, although less frequently. This article presents two cases involving direct relatives, referred after the identification of several basaliomas and jaw cysts. After establishing the diagnosis, given the identification of three major criteria, the treatment consisted in the excision of the lesions followed, in one case, with vismodegib treatment resulting in complete remission. Gorlin-Goltz syndrome is therefore a multidisciplinary challenge, whose variable morbidity and high risk of recurrence make treatment and surveillance critical. However, new molecular targeted therapies have brought a new hope in treating these patients.

Keywords: Basal Cell Nevus Syndrome/diagnosis; Basal Cell Nevus Syndrome/therapy

\section{INTRODUÇÃO}

A síndrome de Gorlin-Goltz, dos carcinomas basocelulares múltiplos, síndrome dos basaliomas nevoides ou, simplesmente, síndrome de Gorlin, é uma patologia autossómica dominante. Com uma penetrância completa, embora de expressividade variável, é causada por mutações inativadoras do gene onco-supressor PTCH1 em 9q22.3-q31, uma proteína inibidora da via Sonic Hedgehog $(\mathrm{SHH})$, interveniente na proliferação e sobrevivência celulares. Rara, com uma prevalência de um caso por cada 56000 a 256 000 indivíduos, é predominantemente causada por mutações herdadas $(70 \%$ a $80 \%$ dos casos), podendo, ainda, resultar de mutações de novo ( $20 \%$ a $30 \%$ dos casos). ${ }^{1-3}$

O seu quadro clínico é caracterizado pelo aparecimento de basaliomas múltiplos de ocorrência precoce, pelo desenvolvimento de queratoquistos mandibulares e de diversas outras alterações de menor frequência, mas que constituem, com as anteriores, critérios major de diagnóstico (depressões palmares ou plantares, calcificações da foice cerebral, anomalias esqueléticas, entre outras). Alterações como fenda labial ou palatina, bossas frontais, hipertelorismo, deformidade de Sprengel, deformidade torácica, alterações vertebrais, sindactilia, quistos ósseos das mãos, macrocefalia, pontificação da sela turca, fibroma ovárico e meduloblastoma, são critérios minor. É, assim, possível estabelecer o diagnóstico na presença de dois critérios major ou de um critério major e dois minor. ${ }^{3-5}$ Além das manifestações descritas, a existência de um familiar em primeiro grau com a doença constitui um critério major adicional.

O tratamento destes doentes constitui um desafio na prática clínica. Dada a multiplicidade e diversidade de lesões, o tratamento cirúrgico nem sempre é possível ou praticável, porém outras opções, como a radioterapia, a longo prazo, contribuir para o aumento de lesões. Recentemente, o desenvolvimento de terapêuticas moleculares dirigidas, como o vismodegib, um inibidor da via Sonic Hedgehog, trouxeram uma nova esperança a estes doentes. ${ }^{1,6,7}$

\section{CASOS CLÍNICOS}

Os autores apresentam dois casos, respeitantes a dois indivíduos da mesma família, referenciados com o diagnóstico de múltiplos carcinomas basocelulares e presença de queratoquistos mandibulares.

1. Serviço de Estomatologia. Centro Hospitalar e Universitário de Coimbra. Coimbra. Portugal.

2. Serviço de Dermatologia e Venereologia. Centro Hospitalar e Universitário de Coimbra. Coimbra. Portugal.

3. Serviço de Anestesiologia. Centro Hospitalar e Universitário de Coimbra. Coimbra. Portugal.

4. Departamento de Dermatologia. Faculdade de Medicina. Universidade de Coimbra. Coimbra. Portugal.

$\triangle$ Autor correspondente: João Mendes-Abreu. jruideabreu@gmail.com

Recebido: 17 de fevereiro de 2016 - Aceite: 14 de novembro de 2016 | Copyright $\odot$ Ordem dos Médicos 2017 


\section{Caso 1}

O caso 1 diz respeito a um doente do sexo masculino com 22 anos, filho de uma doente do sexo feminino, com 53 anos, referida no caso 2. Como antecedentes, o caso 1 apresentava história de meduloblastoma aos 22 meses de idade, tratado com recurso a cirurgia, quimioterapia e radioterapia, tendo o primeiro carcinoma basocelular e queratoquisto sido diagnosticados aos seis e nove anos, respetivamente. Foi submetido a excisão cirúrgica de diversos carcinomas basocelulares e a enucleação de queratoquistos mandibulares. No entanto, a agressividade demonstrada pela doença, traduzida pela presença de um elevado número de carcinomas basocelulares com predomínio no campo previamente irradiado (Fig. 1), levou à implementação de um esquema de terapêutica molecular dirigida. Recorreu-se, para o efeito, ao vismodegib (Erived$\mathrm{ge}^{\circledR}-$ Roche $^{\mathrm{Tm}}$, Basileia, Suíça) via oral, $150 \mathrm{mg}$ id, durante oito meses, com remissão completa de todas as lesões, comprovada histologicamente, após 16 semanas de tratamento (Fig. 2), e efeitos adversos toleráveis, como disgeusia e espasmos musculares de grau 1.

\section{Caso 2}

Relativamente ao caso 2: para além da relação de

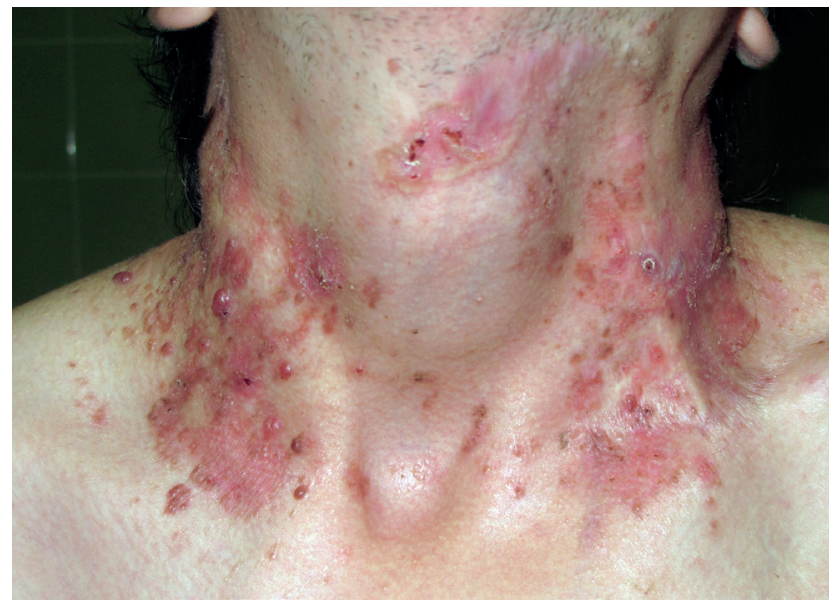

Figura 1 - Múltiplos carcinomas basocelulares (região cervical; caso 1$)$

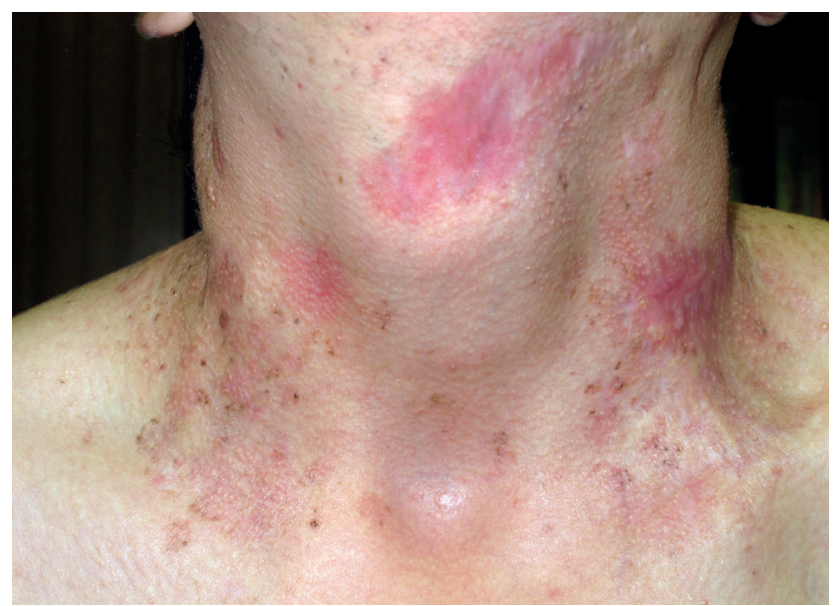

Figura 2 - Evolução da resposta ao vismodegib (região cervical; caso 1) parentesco já descrita, apresentava inicialmente um carcinoma basocelular nodular localizado na pele do lábio superior, tratado por excisão cirúrgica radical (Fig. 3), tendo sequencialmente sido submetida a tratamento cirúrgico de novo carcinoma basocelular da região frontal. Concomitantemente, a realização de uma radiografia panorâmica e, posteriormente, uma tomografia computorizada de feixe cónico, revelaram a presença de uma imagem radiotransparente, de limites regulares e cujas dimensões se sobrepunham às do próprio ramo ascendente esquerdo da mandíbula, tendo o exame anatomopatológico após excisão determinado tratar-se de um queratoquisto (Fig.s 4, 5).

\section{DISCUSSÃO}

Com uma morbilidade muito variável em função do tipo, localização e extensão dos achados clínicos, a síndrome de Gorlin-Goltz representa um desafio de elevada complexidade, traduzido na multidisciplinaridade necessária à sua abordagem. ${ }^{8,9}$

Estabelecido o diagnóstico, perante a identificação de dois ou mais critérios major verificada em ambos os casos (basaliomas múltiplos, queratoquistos mandibulares e ascendência/descendência direta) e, ainda, a contribuição de um critério minor (meduloblastoma) no caso 1 , o passo seguinte passou pelo estabelecimento da estratégia terapêutica. Esta envolveu, primariamente, a remoção radical das lesões cutâneas e a enucleação dos queratoquistos mandibulares, e, num segundo tempo, face ao elevado número de basaliomas presentes no caso 1 , uma terapêutica molecular dirigida com vismodegib..$^{1,6,7}$ No caso 2, contudo, face ao elevado risco de fratura e sequelas, a opção por modalidades conservadoras, no sentido de diminuir a lesão e limitar a perda óssea, como a marsupialização ou a descompressão, previamente à enucleação, são válidas e desejáveis. ${ }^{10}$ Estas, porém, obrigam a níveis de colaboração e de higiene não compatíveis com os encontrados, inviabilizando a sua utilização.

O elevado risco de recorrência destas lesões, assim como o aparecimento de novas, leva a que ambos os doentes sejam submetidos a avaliações regulares. Conclui-se, assim, que é essencial o acompanhamento destes e, pela sua componente hereditária, dos seus familiares,

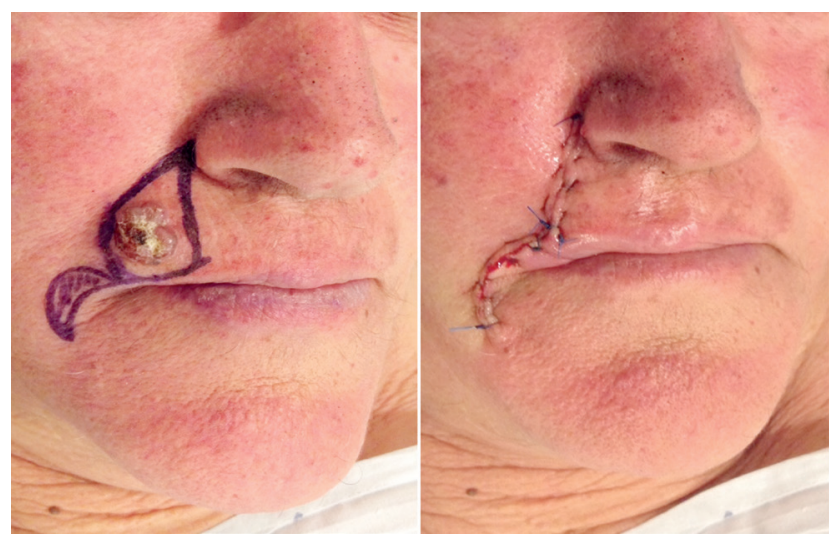

Figura 3 - Carcinoma basocelular do lábio tratado com excisão e retalho (caso 2) 

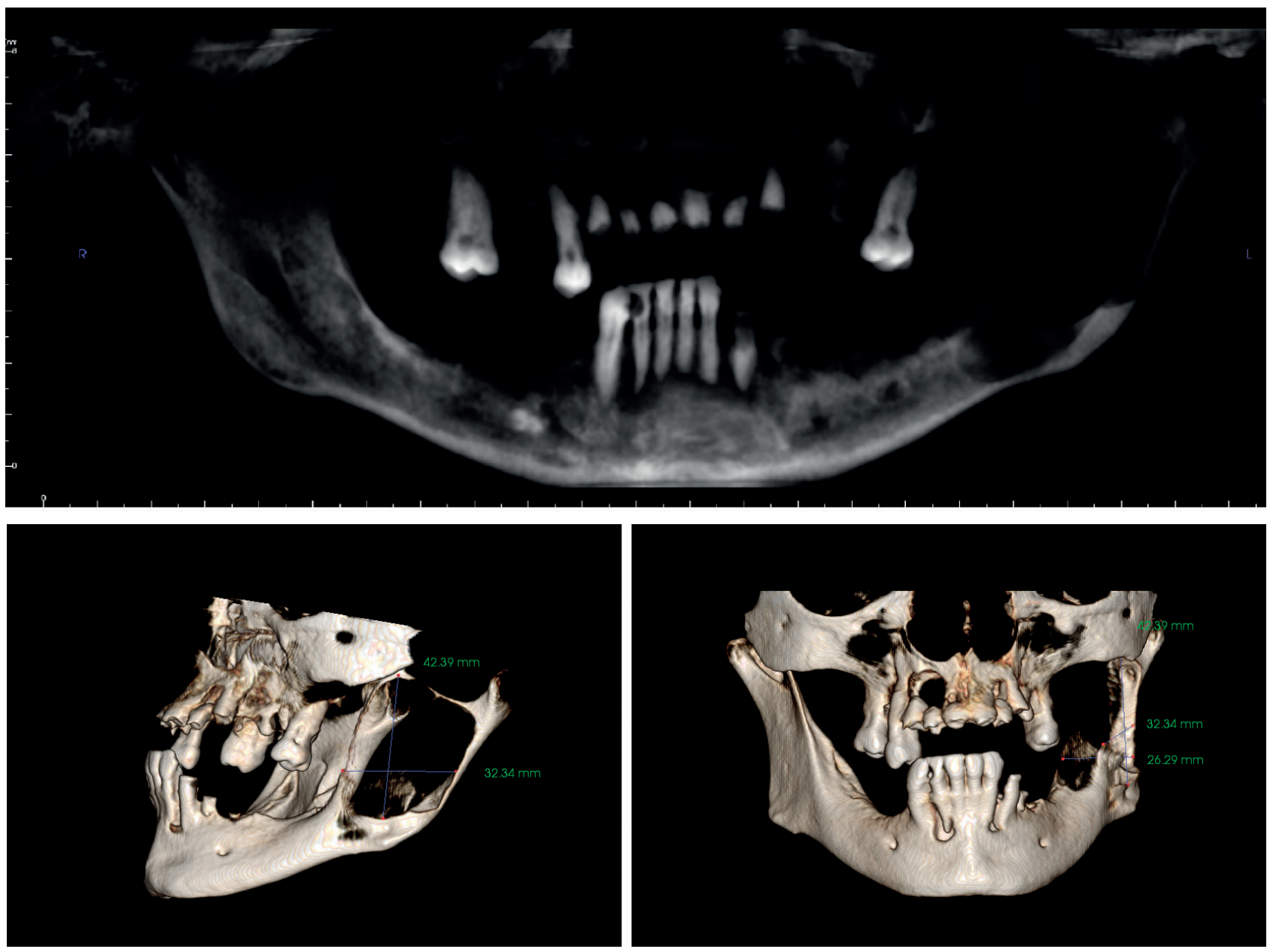

Figura 4 - Radiografia panorâmica e reconstrução tridimensional da mandíbula por tomografia computorizada (caso 2).

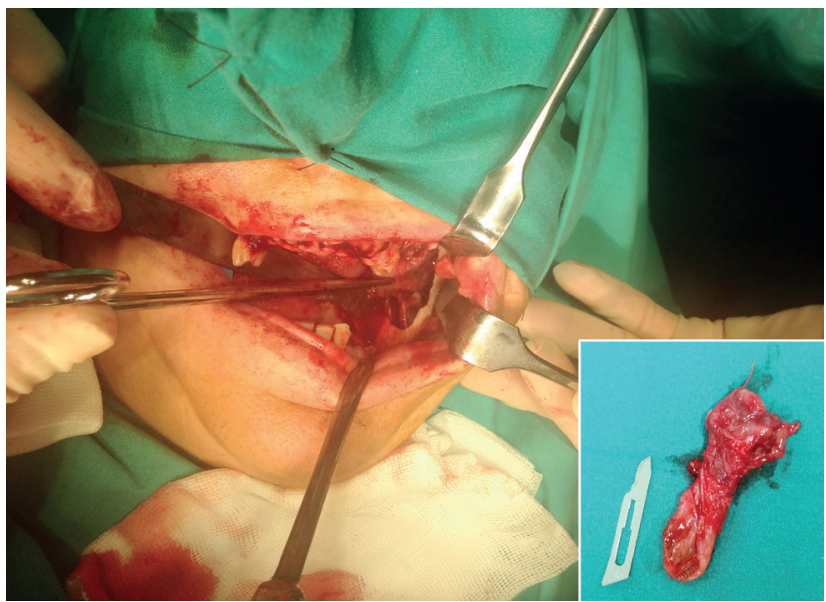

Figura 5 - Observação intraoperatória e ex-vivo queratoquisto (caso 2)

idealmente em contexto multidisciplinar, onde intervirão, além da dermatologia, a estomatologia e cirurgia maxilofacial, entre outras. ${ }^{1,3,6-10}$ Com igual relevância, esta população deve ser alertada para a importância da prevenção do cancro cutâneo, nomeadamente através da adoção de medidas de fotoproteção, como uso de protetor solar e roupa adequada, bem como exposição solar por períodos reduzidos. ${ }^{11,12}$

No tratamento propriamente dito das lesões cutâneas, as novas terapêuticas moleculares constituem uma opção válida, principalmente em casos em que as cirúrgicas não são praticáveis. ${ }^{1,6,7}$

\section{PROTECÇÃO DE PESSOAS E ANIMAIS}

Os autores declaram que os procedimentos seguidos estavam de acordo com os regulamentos estabelecidos pelos responsáveis da Comissão de Investigação Clínica e Ética e de acordo com a Declaração de Helsínquia da Associação Médica Mundial.

\section{CONFIDENCIALIDADE DOS DADOS}

Os autores declaram ter seguido os protocolos do seu centro de trabalho acerca da publicação de dados.

\section{CONFLITOS DE INTERESSE}

Os autores declaram não terem qualquer conflito de interesse relativamente ao presente artigo.

\section{FONTES DE FINANCIAMENTO}

Não existiram subsídios ou bolsas que tenham contribuído para a realização do trabalho. 


\section{REFERÊNCIAS}

1. John AM, Schwartz RA. Basal cell naevus syndrome: an update on genetics and treatment. Br J Dermatol. 2016;174:68-76.

2. Safronova MM, Arantes M, Lima I, Domingues S, Almeida M, Moniz P. Síndrome de Gorlin-Goltz: revisão das características neurorradiológicas e maxilofaciais ilustradas com dois casos. Acta Med Port. 2010;23:1119-26.

3. MacDonald DS. A systematic review of the literature of nevoid basal cell carcinoma syndrome affecting East Asians and North Europeans. Oral Surg Oral Med Oral Pathol Oral Radiol. 2015;120:396-407.

4. Ortega García de Amezaga A, García Arregui O, Zepeda Nuño S, Acha Sagredo A, Aguirre Urizar JM. Gorlin-Goltz syndrome: clinicopathologic aspects. Med Oral Patol Oral Cir Bucal. 2008;13:338-43.

5. Yamamoto T, Ichioka H, Yamamoto K, Kanamura N, Sumitomo S, Shikimori $M$, et al. Nevoid basal cell carcinoma syndrome: Clinical features and implications of development of basal cell carcinoma in skin and keratocystic odontogenic tumor in jaw and their gene expressions. Asian J Oral Maxillofac Surg. 2011;23:105-12.

6. Wolfe CM, Green WH, Cognetta AB, Hatfield HK. Basal cell carcinoma rebound after cessation of vismodegib in a nevoid basal cell carcinoma syndrome patient. Dermatol Surg. 2012;38:1863-6.
7. Ghanaati S, Booms P, Harth M, Sader R. Vismodegib hedgehogsignaling inhibition and treatment of basal cell carcinomas as well as keratocystic odontogenic tumors in Gorlin syndrome. Ann Maxillofac Surg. 2015;5:14.

8. Kimonis VE, Goldstein AM, Pastakia B, Yang ML, Kase R, DiGiovanna $\mathrm{JJ}$, et al. Clinical manifestations in 105 persons with nevoid basal cell carcinoma syndrome. Am J Med Genet. 1997;69:299-308.

9. Fujii K, Miyashita T. Gorlin syndrome (nevoid basal cell carcinoma syndrome): update and literature review. Pediatr Int. 2014;56:667-74.

10. de Molon R, Verzola M, Pires L, Mascarenhas V, da Silva R, Cirelli J, et al. Five years follow-up of a keratocyst odontogenic tumor treated by marsupialization and enucleation: a case report and literature review. Contemp Clin Dent. 2015;6:106.

11. Sánchez G, Nova J, Rodriguez-Hernandez AE, Medina RD, SolorzanoRestrepo C, Gonzalez J, et al. Sun protection for preventing basal cell and squamous cell skin cancers. Cochrane database Syst Rev. 2016;7:CD011161.

12. lannacone MR, Hughes MC, Green AC. Effects of sunscreen on skin cancer and photoaging. Photodermatol Photoimmunol Photomed. 2014;30:55-61. 